\title{
Agricultura Familiar, Gênero e Dinâmicas Sociais: um estudo sobre a construção territorial do assentamento Nova Lagoa Rica ${ }^{1}$
}

\author{
Camila Marques Viana Silva ${ }^{2}$ e \\ Ana Lúcia Eduardo Farah Valente ${ }^{3}$
}

Resumo: Este estudo se refere à análise da experiência de mulheres que buscam, por meio da Associação de Mulheres do Projeto de Assentamento Nova Lagoa Rica (Ampal), no município de Paracatu (MG), um protagonismo no espaço produtivo da agricultura familiar, e de como a questão de gênero se insere no processo de construção territorial desse assentamento, procurando iluminar algumas dimensões da vida comunitária. A pesquisa foi realizada em 2006 e se apoiou na perspectiva técnico-metodológica da Antropologia, que tem como linhas condutoras a exigência do trabalho de campo e o estudo de caso. Os resultados revelam que as práticas que resultam na assimetria das relações entre homens e mulheres continuam sendo reproduzidas no âmbito da agricultura familiar, o que não contribui para a diminuição das desigualdades no campo. Porém, revelam que há um movimento de recusa por parte das agricultoras que, por meio da ação coletiva, têm dado início a um processo emancipatório que as levam a tomar consciência de suas próprias necessidades. Essa análise ainda permite que sejam tecidas algumas considerações a respeito das políticas públicas de apoio à agricultura familiar com recorte de gênero.

Palavras-chaves: Agricultura familiar, gênero, abordagem territorial, reforma agrária, políticas públicas.

Abstract: This paper consists in an analysis about some women who are trying to be, through the Ampal (Associação das Mulheres do Projeto de Assentamento Nova Lagoa Rica, in Portuguese) work experience, in Paracatu (Minas Gerais State), a protagonist in the family farming field. Furthermore, this article tries to understand how the gender issue is inserted in the settlement's process of territorial building, seeking to emphasize

\footnotetext{
1 Este artigo baseia-se na dissertação de mestrado defendida em fevereiro de 2007 da primeira autora, sob a orientação da segunda, apresentada ao Programa de Pós-Graduação Multi-institucional em Agronegócios do Consórcio Centro-Oeste (UnB/UFMS/UFG).

2 Doutoranda em Desenvolvimento Rural (PGDR/UFRGS). E-mail: camila_agro@yahoo.com.br

3 Doutora em Antropologia Social (USP); Pesquisadora e Professora Associada IV (UnB), atuando nos Programas de Pós-Graduação em agronegócios (FAV) e Sociedade, Desenvolvimento e Cooperação Internacional (CEAM). E-mail: alefvalente@gmail.com
} 
some dimensions of communitarian life. The study, conducted in 2006, is based on technician-methodological perspective of Anthropology, which has been conducted by two guidelines: the requirement of the field research and a case study. The results have shown that activities that results in asymmetry of relations between men and women have still been reproduced in the scope of family farming, which does not help to reduce gaps in rural areas. However, it also shows that there is an opposite trend from women agriculturists who, through group work, have started an emancipating process to know their own needs. This analysis also enables to elaborate some considerations about public policies that intend to support family farming with gender emphasize.

Key-words: Family farming, gender, territorial approach, agrarian reform, public policy.

Classificação JEL: R00.

\section{Introdução}

Este estudo tem por objeto a experiência de um grupo de mulheres em um assentamento de reforma agrária no município de Paracatu (MG). Trata-se de problematizar a condição vivida no Projeto de Assentamento (PA) Nova Lagoa Rica que, ao completar dez anos de existência, ainda enfrenta dificuldades para a permanência dos agricultores em suas parcelas de terra. Nessa trajetória, continua reproduzindo práticas que resultam na assimetria das relações de poder entre homens e mulheres, perpetuando a lógica patriarcalista que marca a agricultura familiar.

$\mathrm{Na}$ construção do objeto tem-se por foco principal o estudo do movimento desencadeado pelas mulheres assentadas, visando sua organização. Através de projetos e ações, buscam um protagonismo no espaço produtivo da agricultura familiar, considerando as relações de produção e de poder que o atravessam e que são inseparáveis. Além disso, pretende iluminar algumas dimensões da vida comunitária ao tentar responder as seguintes questões: 1) Onde se dão os espaços de cooperação e como se manifestam os conflitos nas relações entre homens e mulheres no assentamento? 2) Em que medida a inicia- tiva de se organizar representa uma estratégia de resistência das mulheres face às desigualdades de gênero e de recusa/aceitação ao modelo estatal de gestão do assentamento que segue uma lógica capitalista/empresarial? 3) Quais as estratégias de produção adotadas e como as políticas públicas poderiam delas se valer para contribuir com o desenvolvimento desses territórios? 4) Quais são as propostas e limites da atuação estatal e das políticas públicas com recorte de gênero frente ao processo organizativo desses grupos?

A relevância e a justificativa de um estudo como este se sustentam, basicamente, em conhecimentos que vêm sendo acumulados nas análises de gênero, quando referidas ao campo. Estas têm revelado, além da subordinação e da subvalorização do trabalho das mulheres, que as relações no âmbito familiar e a forma como a família é constituída e produzida são tão importantes quanto às relações de classe, quando se trata de explicar a reprodução social da agricultura familiar (PACHECO, 2002).

Do ponto de vista histórico, tal discussão insere-se num contexto em que a agricultura familiar é, pela primeira vez no País, considerada prioridade no discurso governamental, que tem assumido essa categoria social como sujeito 
das transformações necessárias ao campo. Além disso, é também um marco importante por incorporar a questão de gênero na agenda da reforma agrária e do desenvolvimento rural a partir da elaboração de políticas públicas que buscam atender antigas reivindicações das trabalhadoras rurais.

O objetivo deste estudo é, portanto, analisar a ação coletiva de mulheres para melhorar a renda de suas famílias. Mas essa ação avança, dando início a um processo emancipatório que as leva a tomar consciência de suas próprias necessidades e a encontrar os caminhos para superação das dificuldades de reprodução social como agricultoras familiares. Sobre esse movimento é feito um esforço de compreensão sobre como as políticas públicas com recorte de gênero têm dialogado com tais questões.

\section{Metodologia}

$\mathrm{Na}$ construção do objeto, procurou-se relacionar o universal e o singular, pois, segundo Alves (2003, p. 28), "o singular é a manifestação, no espaço convencionado, de como leis gerais do universal operam dando-lhe uma configuração específica". O singular aqui é um assentamento de reforma agrária como parte constitutiva do espaço rural brasileiro, entendendo-o como um território em constante construção onde, de acordo com Raffestin (1993), as relações que envolvem se inscrevem em relações num campo de poder. Convém observar que a análise de tais relações, que são criadas a partir da interação entre os atores e destes com a natureza, é sempre relacional, seja entre homens e mulheres, seja entre comunidade e agentes mediadores, entre poder local e poder público municipal, dentre tantas outras, de modo a contemplar o maior número de dimensões da complexa rede de tessituras que envolve o território em questão.

Neste trabalho, destaque especial é dado à relação entre homens e mulheres, com ênfase no papel desempenhado por estas últimas, o que não significa considerar o olhar feminino como o único ou o melhor ponto de vista, mas como parte de qualquer análise que se proponha entender as relações humanas. Ao propor que essa realidade estudada seja compreendida em sua totalidade por meio da incorporação da questão de gênero, estende-se o uso da noção de trama de tensões, proposta por Ferrante e Barone, também para explicar a construção social da diferença entre os sexos e, consequentemente, as relações desiguais entre homens e mulheres. Desta tensão nascem conflitos, mas também partilhas e sistemas de compensação face às perdas (FARGE e DAVIS, 1991).

O trabalho busca analisar a inserção das mulheres em alguns dos espaços onde a desigualdade se manifesta. Para tanto, dividem-se os espaços pelos quais transitam, utilizando uma nomenclatura usual nos estudos sobre gênero, em: espaço reprodutivo, que se refere ao âmbito do trabalho doméstico, marcado pelo autoconsumo; espaço produtivo, onde a produção agropecuária assume papel principal aliada à crescente participação das atividades não agrícolas e espaço de decisões, que envolve principalmente a interação com o espaço público e as relações de poder que daí derivam.

Metodologicamente, essa pesquisa se apoiou nas linhas condutoras da pesquisa antropológica: a exigência do trabalho de campo e o estudo de caso, caracterizando-se como um estudo de caráter qualitativo.

O levantamento de dados foi realizado de março a outubro de 2006, ou seja, em mais de oito meses de visitas contínuas à comunidade. Para tanto, foram realizadas entrevistas semiestruturadas com 34 mulheres associadas à Associação de Mulheres do Projeto de Assentamento Nova Lagoa Rica (Ampal), o que corresponde a 68\% do total de associadas. Outras informações referentes à Ampal foram obtidas por meio de entrevista mais aprofundada com membros da diretoria, do Sindicato dos Trabalhadores Rurais e técnicos da Ates.

Vale ressaltar a utilização de informações obtidas em 2005, quando uma das pesquisadoras atuou como agente de assistência técnica no assentamento. $\mathrm{O}$ trabalho anterior na comuni- 
dade e a colaboração da pesquisadora no desenvolvimento de alguns projetos facilitaram a abordagem junto às agricultoras.

\section{Espaços divididos, espaços compartilhados: o lugar da mulher nos espaços de decisão, reprodutivos e produtivos do P.A. Nova Lagoa Rica}

O município de Paracatu ${ }^{4}$, com uma quantidade imensa de terras improdutivas e abandonadas de Cerrado, passou a ser alvo dos movimentos de ocupação no final da década de 80. Após uma experiência fracassada e uma fase de acampamento pouco conflituosa, a Fazenda Lagoa Rica foi desapropriada em 1996, criando-se o Assentamento Nova Lagoa Rica, constituído por 111 famílias. Analisando-se a trajetória desse assentamento, verifica-se um quadro de desmobilização que há tempos vem se desenhando, resultado da forma como os projetos foram conduzidos e de conflitos políticos oriundos das disputas de poder, tanto no âmbito comunitário quanto municipal.

Diante de tal conjuntura, em 2004, um grupo de mulheres resolveu criar uma comissão no âmbito da associação comunitária com o intuito de desenvolver projetos de geração de renda específicos para elas. Meses depois foi transformada na Associação de Mulheres do PA Nova Lagoa Rica (Ampal).

Para problematizar a participação da mulher no conjunto de diferentes tempos e espaços dessa complexa construção que é um assentamento de reforma agrária, procurando explicitar os mecanismos de inclusão/exclusão da mulher no núcleo familiar e na comunidade, este trabalho divide-se a partir da análise do espaço reprodutivo, que se refere ao âmbito do trabalho doméstico, marcado

4 Paracatu situa-se na região noroeste de Minas Gerais e fica a $220 \mathrm{~km}$ de Brasília e a $482 \mathrm{~km}$ de Belo Horizonte. A cidade foi fundada no final do ciclo do ouro, tomando impulso com a construção de Brasília e com a expansão da fronteira agrícola para o Centro-Oeste. pelo autoconsumo; do espaço produtivo, onde a produção agropecuária assume papel principal aliada à crescente participação das atividades não agrícolas e do espaço de decisões, que envolve principalmente a interação com o espaço público e as relações de poder que daí derivam.

Como na prática esses espaços não se separam, já que um não existe independente do outro, trata-se de uma divisão meramente didática a fim de explicitar os aspectos marcantes de cada dimensão mencionada. O desafio aqui proposto é problematizar em que medida a divisão e o compartilhamento dos espaços têm limitado ou permitido, respectivamente, mudanças no quadro de distribuição de poder no âmbito da agricultura familiar e, portanto, se têm proporcionado ou não, a possibilidade de que essa categoria social configure-se como território privilegiado para diminuição das desigualdades.

\subsection{Espaço reprodutivo (autoconsumo)}

Esse espaço, que é marcado pelo autoconsumo, abriga a realização de atividades que garantem a reprodução da família, como criação dos filhos, alimentação e saúde. Ou seja, o controle da atividade reprodutiva coloca o trabalho doméstico no centro da discussão, já que é onde a mulher desempenha atividades que têm a ver com a reprodução física. Antes, porém, de tratar das relações que se estabelecem no âmbito doméstico, é necessário conhecer a estrutura familiar, uma vez que esta tem influência decisiva nas relações de gênero (RUA e ABRAMOVAY, 2000, p. 172).

As famílias são, em quase $100 \%$ dos casos, nucleares, e constituídas, em média, por quatro pessoas. Esse número é relativamente pequeno, se comparado ao imaginário que se tem das famílias no meio rural, o que não se deve a uma diminuição no número de filhos, mas ao desmembramento destas com a ida para o assentamento, já que muitos filhos não acompanharam os pais. Alguns por não compartilharem da mesma vontade de viver no campo e, a maioria, pela falta de oportunidades de emprego e estudo. Ou seja, 
as famílias continuam numerosas, embora o que diminua a cada dia é o número de membros dispostos a viver no assentamento. A situação mais encontrada foi de lares constituídos por marido, mulher, filhos pequenos ou adolescentes e netos.

Outro aspecto relevante refere-se à renda das famílias que, em cerca de $60 \%$ dos casos, é proveniente de mais de uma fonte. O trabalho fora da propriedade representa uma estratégia da qual podem lançar mão em situações difíceis, sendo o mais comum trabalhar em fazendas da região ou fazendo 'bicos' no próprio assentamento. $\mathrm{O}$ programa Bolsa Família, apesar de beneficiar boa parte das famílias - pelo menos todas as que têm filhos em idade escolar - representa pequena parte da renda, salvo dois casos em que as famílias contam apenas com este benefício. Já as aposentadorias e pensões geram um grande impacto para um terço das famílias, representando mais de $50 \%$ da renda nesses casos. Apesar de ser a única fonte de renda para apenas $23 \%$ dos casos analisados, a venda de produtos agropecuários representa uma parcela importante para mais de $70 \%$ das famílias, configurando-se numa atividade que ainda é a base para a organização familiar e para a divisão do trabalho, fazendo parte, em maior ou menor medida, do cotidiano de cada assentado.

Para metade das mulheres, o marido é o único responsável pelo sustento da família. As outras, porém, tem consciência de que também contribuem, mesmo com seu trabalho não monetariamente remunerado. Nesses casos, no entanto, computa-se apenas o trabalho que realizam no espaço produtivo, não considerando a importância do trabalho doméstico para o consumo. De modo geral, as atividades comumente desempenhadas pelas mulheres no espaço reprodutivo são: cuidados com os filhos e com a casa; preparo do alimento; fabricação de sabão; preparo de xaropes medicinais, de gorduras, conservas e doces; confecção ou conserto de roupas; fabricação de artesanato; lida com o quintal, onde produzem verduras, frutas, flores e criam pequenos animais, geralmente porcos e galinhas. Observa-se que a diversidade de alimentos produzidos no quintal possibilita um consumo balanceado, representando fontes importantes de nutrientes.

A participação do homem no trabalho doméstico, quando acontece, geralmente se refere ao auxílio nas atividades relacionadas ao quintal ou à lida com os pequenos animais. Nos casos em que os maridos ajudam com frequência, tanto o homem quanto a mulher possuem maior grau de instrução e são mais engajados com o movimento sindical, comparando-se à média da comunidade. Sobre a valorização do trabalho feminino pelos maridos, a maioria das entrevistadas respondeu que acha que estes valorizam seu trabalho, sendo que somente em três casos, responderam enfaticamente que não há valorização por parte dos maridos. Outras disseram que eles valorizam "quando querem".

Com relação à criação dos filhos, na opinião dos homens, a responsabilidade é dos dois, concordando que devam compartilhar tarefas como levar para escola ou participar de reuniões de pais, por exemplo. Mas reconhecem que, no final das contas, as mulheres "acabam fazendo tudo sozinha mesmo", pois para eles "a mulher tem mais tempo".

Sobre a condição de divisão ou compartilhamento desse espaço, considerou-se a distribuição de responsabilidades de modo que foi possível confirmar que espaço do autoconsumo é exclusivamente feminino. A responsabilidade por todo o gerenciamento do espaço não implica, porém, poder de decisão. A mulher enfrenta a difícil condição de não decidir por recursos controlados por ela. Notou-se também como a desvalorização está associada ao desrespeito e à violência, tanto física como emocional. O depoimento abaixo é exemplo disso:

\footnotetext{
"Meu marido pegou o dinheiro do banco (Pronaf) e foi pra cidade beber. Volta e meia, ele faz isso. Some e me deixa sozinha com um monte de filhos sem ter o que de comer, nem como plantar. Os menino tudo pequeno não pode ajudar muito e não tem dinheiro nem pra comprar uma semente. Só não passamo fome por causa
} 
da ajuda de vizinhas. Quando o dinheiro dele acaba, ele volta pra casa para me maltratar e ainda mostra fotos com outras mulheres para os filhos. Como o lote é no nome dele, não posso fazer nada. Tenho que aguentar porque não tenho pra onde ir" (Agricultora).

Nesse caso, o problema maior está ligado à falta de poder de barganha da mulher, numa situação em que não é titular do lote ${ }^{5}$. Por mais que seja atribuído à mulher o papel de garantir a reprodução física, não é considerada a beneficiária do crédito (Pronaf) destinado ao custeio anual da lavoura de onde se tira a base da alimentação da família. Ela fica impossibilitada de decidir efetivamente sobre os produtos obtidos pela aplicação deste, ou até mesmo se a destinação dada ao dinheiro recebido beneficiará a família. Certamente isso se repete com relação aos outros benefícios destinados ao desenvolvimento da produção.

Essa análise das relações que se dão no âmbito doméstico permite compreender em quais momentos a colaboração, a violência e a disputa se manifestam. Ou seja, quando é divido e quando é compartilhado. Além disso, possibilita enxergar como são importantes as múltiplas atividades desempenhadas pelas mulheres que, mesmo dividindo a jornada de trabalho entre a casa e o roçado, ainda são responsáveis por uma série de outras atividades, como resolver problemas na cidade ou mesmo trabalhos comunitários no próprio assentamento, como limpar a igreja ou ser voluntária da Pastoral da Criança, por exemplo.

\subsection{Espaço produtivo}

O espaço produtivo é caracterizado por uma heterogeneidade nas estratégias de produção levadas a cabo pelas famílias pesquisadas.

\footnotetext{
5 Seguindo a argumentação de Argawal citada por Deere e León (2002, p. 44), a posse e o controle da terra aumentam as possibilidades produtivas da mulher e a probabilidade de ela ter acesso a crédito, suporte técnico e mais informação.
}

Nos primeiros anos de assentamento, a produção se orientou em torno da atividade leiteira. Entretanto, a comercialização garantida para uma grande cooperativa do município não foi capaz de manter a sustentabilidade da atividade, uma vez que os preços pagos pelo leite não pagavam sequer seu custo de produção. Das famílias entrevistadas, somente cinco ainda entregavam leite para a cooperativa.

Na região estudada, a atividade leiteira é predominantemente masculina. Com a desistência de seus maridos de 'entregar o leite', muitas mulheres passaram a exercer um papel central por meio da fabricação do queijo, única alternativa que restou. A comercialização, no entanto, se dá por meio de mecanismos frágeis, como a venda de porta em porta e a venda sem contrato para fábricas de biscoito ou padarias, uma vez que não se tem certificação sanitária.

O excedente da produção agropecuária, principalmente milho, arroz e mandioca, é vendido dentro do próprio assentamento para famílias que não têm área de cultivo, ou para atravessadores. Quem tem melhores condições leva os produtos para vender na cidade por conta própria. Um problema recorrente na comercialização é o assentado entregar o produto e não receber, já que não há nenhum tipo de contrato de venda.

Quanto à agroindustrialização da produção, uma alternativa adotada pelos assentados é a produção de farinha, devido ao aumento crescente no consumo de farinhas da região, que chegam a custar $\mathrm{R} \$ 0,40 / \mathrm{kg}$ a mais que a farinha vendida nos supermercados, geralmente oriunda do Paraná e do Pará. A produção de rapadura também foi bastante estimulada, dadas as condições de solo propícias ao plantio da cana e a facilidade na comercialização para alambiques da região que fabricam cachaça a partir da rapadura. Os assentados trocam $2 \mathrm{~kg}$ de rapadura por 1 litro de cachaça, que é mais fácil de vender depois. Como a cachaça de rapadura é mais cara que a comum, o litro é vendido por $\mathrm{R} \$ 5,00$ e os assentados lucram $\mathrm{R} \$ 0,60$ a mais comparando com o que receberiam da venda direta da rapadura para o comércio local. 
Outra forma de comercialização desses produtos é por meio do Programa de Aquisição de Alimentos da Agricultura Familiar (PAA), executado pela Companhia Nacional de Abastecimento (Conab). Em 2004, todo o estoque de farinha do assentamento foi comercializado por meio desse mercado institucional.

O que foi mencionado até aqui permite visualizar o mosaico de estratégias desenvolvidas pelos assentados, mas não mostra a variedade de situações enfrentadas pelas famílias. A visão de um assentamento onde todos compartilham a mesma situação é logo quebrada ao analisar de perto as singularidades oriundas dos diferentes pontos de partida de quem é primeiro, segundo, terceiro ou quarto ocupante do lote. Por exemplo, não se pode comparar o caso bem-sucedido de criação de frangos por um assentado ex-funcionário público que adquiriu o lote mediante compra e com algum capital disponível para investir na atividade, com uma assentada solteira que tem cinco filhos pequenos e vive com o benefício do programa Bolsa Família. Mas também não se pode desconsiderar que suas trajetórias ora os individualizam, ora os aproximam (FERRANTE, 2000) e, sendo assim, o caso relativamente bem-sucedido pode servir de exemplo quando se pensa em projetos para a comunidade.

A maioria das mulheres dedica boa parte do tempo no espaço produtivo dos lotes, realizando atividades como capina, plantio, colheita, destoca, beneficiamento, entre outros, mas sem interferência/intervenção na comercialização dos produtos. No acesso ao crédito, a participação da maioria das mulheres se resume a assinar conjuntamente a Declaração de Aptidão ao Pronaf (DAP). Em todo o município, nenhuma assentada conseguiu acessar o Pronaf Mulher, sendo o endividamento dos maridos uma das principais causas. As poucas que possuem condições de acesso desistem ao esbarrar na burocracia imposta pelo agente financeiro.

O que se verificou ao analisar o espaço produtivo é que este só é compartilhado entre homens e mulheres quando se trata de trabalho. Quando o assunto é decisão, ou seja, sobre a elaboração do projeto produtivo e as estratégias a serem adotadas, o espaço é exclusivamente masculino.

\subsection{Espaço de decisões}

Segundo Lima et al. (1995), as decisões dos agricultores familiares visam atender um ou mais objetivos no quadro de ações percebidas como possíveis pelo grupo familiar, tendo em vista a percepção que os agentes têm de uma situação e das finalidades atribuídas às suas unidades de produção. Entretanto, cabe a preocupação em conhecer como essas decisões são tomadas e se realmente atendem aos interesses de toda a família, principalmente no que se refere à participação das mulheres nesse processo.

Analisando os espaços reprodutivo e produtivo, ambos no âmbito da unidade agrícola familiar, as decisões que realmente impactam a vida da família são tomadas pelos homens que, vez ou outra, consultam suas esposas. Nesse tópico, será tratada a participação das mulheres no contexto da comunidade.

Sendo o assentamento um território, onde se supõe que a gestão deva ser coletiva, voltamos a atenção para o papel das mulheres nas decisões comunitárias por meio da participação em reuniões e assembleias do assentamento. A presença das mulheres sempre esteve condicionada à pauta de discussões e, principalmente, ao horário das reuniões, sendo assim, sempre compareceram em menor número. De modo geral, pouco se manifestavam e quando o faziam, não eram ouvidas. Poucas tinham direito ao voto, pois para isso precisavam pagar a associação. Como o mais comum é que apenas um membro da família seja associado - geralmente, os homens titulares - as mulheres "naturalmente" eram excluídas da tomada de decisão.

A reclusão dessas mulheres ao âmbito privado estabelecia limites para sua participação nos assuntos da coletividade, restringindo sua mobilidade e atividade política. Isso fez com que elas pouco decidissem sobre os rumos do assentamento ao longo dos anos, como, por exemplo, na escolha de projetos a serem desenvolvidos 
ou na destinação de recursos públicos para a comunidade.

Por meio de um estímulo do Sindicato dos Trabalhadores Rurais de Paracatu/Guarda-Mor - STR foi criada uma comissão de mulheres no âmbito da associação comunitária. Inicialmente, tiveram problemas em mobilizar e constituir a articulação desse grupo, pois não havia clareza de qual seria o interesse coletivo prioritário em torno do qual uniriam esforços. Assim, houve a participação de poucas mulheres, que se ocuparam das discussões para definição das diretrizes a serem tomadas pela comissão. Ainda assim, se organizaram e conseguiram o primeiro recurso, por meio do Programa Mutirão Segurança Alimentar e Nutricional do Estado de Minas Gerais (Prosan), que previa a liberação de $\mathrm{R} \$ 13.000$ para a criação de frango de corte e galinhas poedeiras, conforme escolha das mulheres. $\mathrm{O}$ fato de as mulheres estarem representadas na comissão, no entanto, não mudou o fato de não terem poder de decisão nas assembleias e reuniões da associação. A falta de autonomia foi ficando insustentável até o momento em que precisaram da primeira assinatura do presidente justamente para liberação do recurso do Prosan que, somente depois de muita pressão, resolveu assinar os documentos.

Diante de tal situação, as mulheres do PA Nova Lagoa Rica perceberam que poderiam contar pouco com o apoio da associação comunitária para colocar em prática seus projetos. A gota d'água foi quando o presidente disse a elas que "mulher só serve para cozinhar e parir". Revoltadas, elas resolveram declarar independência e constituir sua própria associação, a Ampal. Não satisfeito, o presidente da associação comunitária tentou de todas as formas desestimulá-las, alegando que fundar uma associação não era uma tarefa fácil e que, portanto, jamais conseguiriam.

A criação da associação de mulheres foi e ainda é vista por muitos assentados como uma questão de disputa política, como mera oposição à diretoria da associação comunitária na época. As líderes do movimento das mulheres alegam, entretanto, que não se trata de disputa de poder, mas de uma maneira que encontraram de conquistar um espaço onde seus interesses fossem contemplados. Apesar da desaprovação de grande parte da comunidade, dos maridos e dos dirigentes locais do movimento sindical, a associação de mulheres foi se estruturando, alicerçada pelo apoio financeiro obtido pelo Prosan. Animadas com o projeto de criação de frango, em poucos meses, muitas mulheres associaram-se. Após poucos meses, já eram 50 sócias, das quais 10 eram da comunidade vizinha, do Projeto de Assentamento Aracaju.

Depoimentos das mulheres permitem afirmar que a associação surge como uma expressão de recusa face à discriminação, aliada ao quadro de precariedade vivido por suas famílias. A lógica que norteou sua formação, portanto, está ligada a uma ação de resistência, mas principalmente à necessidade de geração de renda.

Paralelamente à criação da Ampal, o recurso do Prosan foi liberado, com restrições e reformulações que reduziram o valor a $\mathrm{R} \$ 3.066,00$ menos de $25 \%$ do total - inviabilizando o projeto como fonte de geração de renda. Essa situação foi agravada pela impossibilidade da comunidade em colaborar com alguma contrapartida. Com o valor disponibilizado só foi possível comprar uma pequena quantidade de galinhas e pintinhos, além de um pouco de ração, tornando a atividade economicamente inviável. A coordenadora do Conselho Municipal de Segurança Alimentar e Nutricional (Comsea) aconselhou, então, que as galinhas e frangos fossem utilizados para o consumo da família, já que se tratava de programa de segurança alimentar. Esse problema, porém, não foi suficiente para desanimar as mulheres que enxergavam nesse recurso apenas um 'ponta pé' inicial para a criação de frango caipira, atividade escolhida pela facilidade de comercialização e os bons preços obtidos pelo produto na região.

Em 2005, diante do quadro de esvaziamento da associação comunitária, a Ampal ganhou uma dimensão que a colocou como principal organização dentro do assentamento. As reuniões, cada vez mais lotadas, e a animação das mulheres fizeram com que diminuísse a hostilidade inicial de 
quem não concordava com sua constituição e ainda estimulou a formação de grupos de mulheres nos outros assentamentos do município.

No primeiro semestre de 2006, a falta de resultados concretos das iniciativas tomadas em 2005, aliada ao desentendimento entre a presidente e a vice da Ampal, culminado com o afastamento desta última, fizeram com que houvesse uma desmobilização das mulheres. As reuniões passaram a ser realizadas somente uma vez por mês, se transformando em um momento de descontração das mulheres que passaram a utilizá-lo para interagir umas com as outras e colocar a "conversa em dia". No segundo semestre, houve um novo impulso pela aprovação de dois projetos: um que previa a construção de uma cozinha comunitária na igreja do assentamento, e o outro por meio do Prosan que, a partir de 2005, passou a não mais liberar recursos para a criação de pequenos animais, o que fez as mulheres optarem pela aquisição de mudas de frutas. Tais projetos também não eram voltados para a geração de renda.

Para entender o processo de participação no âmbito da Ampal, apresentam-se alguns dados importantes sobre a condição das associadas. Dentre as mulheres entrevistadas, $70 \%$ são originárias da região noroeste de Minas Gerais, sendo $40 \%$ de Paracatu. A maioria (aproximadamente $80 \%$ ) tem mais de 40 anos, são casadas e já não têm os filhos morando consigo. Observa-se pouco interesse das mulheres com idade inferior aos 40 anos nas atividades da associação e a inexistência de sócias com idade inferior a 20 anos é explicada em parte pela existência de uma comissão de jovens no assentamento. No caso das duas únicas solteiras, cabe ressaltar que o fato de serem titulares dos lotes não representa, na prática, melhores condições de vida para essas famílias, pois sozinhas não têm como produzir. Isso reforça o princípio de que apenas a titulação não é condição para garantir a sobrevivência de suas famílias.

Quando considerada a escolaridade dessas mulheres, constatou-se que $65 \%$ só estudaram os quatro primeiros anos do ensino fundamental. Apesar de ser um importante indicador para perceber relações de dominação/supressão entre campo e cidade, não foi percebida interferência entre o índice de escolaridade e o envolvimento destas mulheres com os assuntos de interesse coletivo da comunidade. Essa correlação foi verificada cruzando-se os dados do questionário e a partir da vivência anterior da pesquisadora no assentamento.

Sobre a participação nas atividades da associação, tem-se que, mesmo em tempos difíceis, as mulheres sempre comparecem às reuniões, com frequência acima de 50\%. Esta, por sua vez, está relacionada ao interesse nos assuntos da associação, mas também ao fato de ser uma das únicas ocasiões que as mulheres se encontram todas juntas, ou seja, assim como a igreja, por exemplo, esse é um espaço onde a rede de sociabilidade é fortalecida. A participação, entretanto, merece ser problematizada já que não se refere especificamente à presença das mulheres nas reuniões, assembleias e outros eventos. Verifica-se que, quando se trata de efetivamente participar das decisões, das atividades propostas e, principalmente, de colocar em prática encaminhamentos, a maioria das mulheres aguarda o posicionamento da diretoria, resultado, em parte, dos limites do modelo de gestão hierarquizado adotado pela associação que coloca toda a autoridade e os encaminhamentos sob a responsabilidade da presidente. Ao questionar as mulheres a respeito de sua ajuda na associação, as respostas permitem afirmar que a encaram como um espaço delas, principalmente pela abertura para opinar, mas acham que poderiam melhorar com relação à participação e muitas reclamam por mais união, e sugerem que deviam ficar mais tempo juntas além das reuniões, indicando uma atividade coletiva como solução. Um dos exemplos citados foi a realização de feiras de troca interna.

Outra questão muito citada no grupo é a necessidade de capacitação, aparentemente, mais por reproduzirem o discurso vigente de que os assentados precisam se capacitar do que, necessariamente sentirem necessidade de formação específica. Sinaliza nessa direção o fato de não saberem apontar o tipo de capacitação a ser rei- 
vindicada. Além disso, sentem vontade de ajudar mais o grupo, mas consideram ser muito difícil, pois para isso precisariam deixar suas casas sozinhas. Dessa forma, uma atividade coletiva na associação, sem uma negociação da divisão de tarefas em casa, ocasionaria numa sobrecarga para a mulher que já exerce dupla jornada de trabalho.

Apesar das dificuldades enfrentadas e de, até o momento estudado, não terem conseguido colocar em prática nenhum projeto coletivo de geração de renda, as mulheres indicam que aprenderam muito depois que passaram a participar da Ampal e que isso trouxe mudanças significativas às suas vidas. Elas afirmam, por exemplo, ter aprendido a conviver mais umas com as outras, que se integraram mais com a comunidade e que o trabalho em grupo faz com que tenham maior compromisso e responsabilidade com o assentamento, além de valorizarem mais o trabalho feminino.

De acordo com a proposta inicial de verificar as transformações no modo de vida dessas mulheres, tem-se que a constituição da associação e a ação coletiva dela decorrente promoveram alguns benefícios, tais como: fortalecimento organizacional; construção de redes e alianças sociais; aprofundamento de normas e valores (tais como a solidariedade, a reciprocidade, a confiança) que contribuem para o alcance do bem comum; modificação das relações sociais no interior do assentamento e, particularmente, as relações de poder (no caso, ligadas a questões de gênero) com influência sobre as políticas públicas, a partir do maior acesso à tomada de decisão e ampliação das oportunidades de desenvolvimento, de modo a enfraquecer ou superar os sistemas de exclusão e de discriminação.

Ressalta-se que ainda não foi observado nenhum impacto significativo das principais políticas públicas formuladas no governo petista visando atender às reivindicações das trabalhadoras rurais. Trata-se do Pronaf Mulher, da Titulação Conjunta da Terra e de outras ações ligadas à promoção da igualdade de gênero na reforma agrária.
Com relação aos cursos e projetos realizados na Ampal, dois casos são emblemáticos de como as intervenções públicas devem se atentar para as mudanças que podem vir a causar nas relações sociais e as circunstâncias que as reproduzem. No que se refere à capacitação, por exemplo, as comunidades assentadas do município contam com o Serviço Nacional de Aprendizagem Rural (Senar), sendo comum a solicitação de cursos pelos assentados. Um exemplo de como esses cursos são oferecidos pode ser observado a seguir: em 2004, enquanto ainda formavam a comissão, as mulheres pediram um curso para aprender a fabricar derivados de leite, além do queijo. Ao chegar à comunidade, entretanto, a técnica dessa instituição fez com que as mulheres lavassem três lugares diferentes - a cozinha da escola e duas salas da agroindústria - para a realização do curso e, no final das contas, disse que nenhum se adequava às exigências sanitárias, cancelando o curso. As mulheres, que guardaram leite de dois dias para levar para o curso, perderam o leite, o tempo e a vontade de fazer curso novamente. $\mathrm{Ou}$ seja, de nada adianta tentar capacitar as agricultoras sem uma discussão prévia das exigências legais previstas para a realização de determinada atividade produtiva.

Outro caso ocorrido foi a seleção da Ampal como beneficiária do Projeto de Apoio a Grupos Produtivos, executado pelo antigo Programa de Promoção da Igualdade de Gênero, Raça e Etnia do Ministério do Desenvolvimento Agrário (PPIGRE/MDA), com o objetivo de incentivar grupos de mulheres rurais que desempenham alguma atividade produtiva, através de apoio técnico e financeiro. A associação se inscreveu em junho de 2005 e ficou sabendo apenas que havia sido selecionada na primeira das três fases do processo de seleção, sendo a notícia da aprovação uma injeção de ânimo para a comunidade. Entretanto, após solicitar a documentação da associação, o MDA não entrou mais em contato, somente retomado quando foi solicitada a presença de um responsável pela associação em São Paulo para explicar como seria a execução do projeto já em agosto de 2006. Lá, as mulheres tiveram 
que escolher entre três instituições para executar o projeto: uma empresa de Ater que não tem atuação em Minas Gerais; a Emater, que praticamente não atua nos assentamentos de Paracatu ou a Contag, escolhida pela presidente da Ampal. O MDA não havia articulado antes com tais instituições, cabendo aos grupos fazerem a proposta para a instituição e esperar que esta aceitasse. A última notícia que a Associação teve sobre o projeto, em novembro de 2006, é que a Contag e o MDA ainda iriam conversar sobre o assunto.

Teoricamente, o referido projeto funcionaria da seguinte forma: com base em questionários aplicados na comunidade, a instituição escolhida para executar o projeto elaboraria um plano de trabalho propondo ações de capacitação para solucionar os problemas mais críticos do processo produtivo. Na reunião com o MDA, a presidente da Ampal explicou os problemas que fizeram com que o grupo ainda não estivesse produzindo coletivamente, pois, além da falta de recursos financeiros para aumentarem a produção de frangos destinada ao autoconsumo, precisariam de um abatedouro e, principalmente, que o município tivesse Serviço de Inspeção Municipal (SIM) para que pudessem comercializar os frangos, sem que fosse preciso fazê-lo clandestinamente, por meio de canais de comercialização incertos e inseguros. A equipe responsável pelo projeto, entretanto, transferiu a responsabilidade de resolver essas questões para a instituição que viria a ser a executora do projeto. Ou seja, mesmo que o projeto tivesse prosseguido, pouca coisa mudaria na situação dessas mulheres que seriam 'capacitadas para alguma coisa', mas continuariam sem condições de produzir.

Nesse contexto, conclui-se que alguns programas governamentais e não governamentais terminam por fragilizar as organizações ao provocar expectativas não cumpridas. Ao invés de darem suporte ao envolvimento de mulheres rurais em projetos produtivos de modo a incidir na transformação das estruturas, ajudando a construir finalmente a participação das mulheres na produção e reprodução social em condições mais equitativas, da forma como são pensados, ou seja, longe da realidade dos agricultores, resultam em frustração e desmobilização dos grupos.

De modo geral, o que se tem notado é que, apesar de a vasta produção acadêmica sobre os assentamentos rurais enfatizar a necessidade de conhecimento da realidade quando da elaboração de políticas públicas, seus formuladores e operadores continuam distantes da realidade das comunidades.

\section{Conclusões}

Com a intenção de estudar a experiência de um grupo de mulheres no PA Nova Lagoa Rica, no município de Paracatu (MG), com base no movimento por elas desencadeado visando sua organização, foram formuladas quatro questões de pesquisa que procuramos responder ao longo desse artigo. Uma breve síntese pode ser feita a seguir.

De modo geral, constata-se que a constituição da Ampal é resultado de uma ação de resistência das mulheres e de recusa ao modelo estatal de associativismo que não leva em conta a existência das desigualdades e dos conflitos no interior dos assentamentos, e que pensa a constituição desses territórios como um processo linear. Além disso, a iniciativa de se organizar deve ser compreendida a partir do quadro de precariedade em que vivem, já que o principal desafio é desenvolver uma atividade que gere renda para aumentar a qualidade de vida de suas famílias. Conforme anuncia Ferrante (2000), a partir de estudo em assentamentos no estado de São Paulo, esses grupos de mulheres vêm contrariando o viés patriarcal presente no projeto estatal de assentamentos, enfatizando a importância da significativa rede de novas relações que têm tecido.

Verifica-se que a criação da Ampal contribuiu para que houvesse mudanças importantes nas relações de poder no nível comunitário, como o fato de ser consultada pela Associação Comunitária nas decisões que impactam o assentamento. Em contrapartida, não foi observada nenhuma mudança nas relações no âmbito da 
família. Isso pode ser explicado pelo fato de não terem conseguindo ainda participar de uma atividade que gere renda permanente e regular, o que provavelmente aumentaria o poder de barganha dessas mulheres, e que poderia mudar a correlação de forças no processo da tomada de decisão.

A análise dos espaços reprodutivo, produtivo e de decisões, permite perceber que o conflito e a cooperação estão presentes nos diferentes tempos e espaços, ora divididos, ora compartilhados, numa relação dialética, mas que coloca a mulher sempre em uma posição de desigualdade. $\mathrm{Ou}$ seja, além da dupla jornada de trabalho exercida, do caráter de 'ajuda' do trabalho produtivo, a relação entre homens e mulheres, tanto no âmbito doméstico como na comunidade, é marcada por uma assimetria em que a mulher pouco participa da tomada de decisão.

Em que pesem as controvérsias sobre o formato adotado pela política agrícola e agrária no País e os problemas graves a serem solucionados nos assentamentos, são percebidas transformações positivas para o conjunto das famílias beneficiadas e a dinamização gerada em muitas regiões, uma vez que os assentados puderam ter acesso ao crédito rural e a outras políticas públicas. Entretanto, essas transformações não têm sido suficientes para garantir a produção e reprodução social dos agricultores familiares. No assentamento estudado, considerando as estratégias familiares criadas na luta pela sobrevivência, percebe-se que há uma constante reinvenção por parte dos agricultores na tentativa de se alcançar a sustentabilidade, nem sempre contemplada em todas as dimensões. Na busca de alternativas, as mulheres desempenham um papel decisivo, mesmo que ainda desvalorizado. Desse modo, impõe-se a incorporação da questão de gênero nas análises a respeito da agricultura familiar e reforma agrária, assim como outras categorias de análise - pluriatividade, multifuncionalidade, sustentabilidade, capital social, desenvolvimento territorial - diante das transformações no meio rural, entre as quais se destaca a crescente participação das atividades não agrícolas na renda das famílias rurais.
Nesse contexto, convém observar que, no que tange às relações de gênero, segundo Ortner (1979, p. 118), os esforços dirigidos unicamente na mudança das instituições sociais não podem ter efeitos de longo alcance se a linguagem e as figuras culturais continuam a fornecer uma imagem relativamente desvalorizada da mulher. Mas, ao mesmo tempo, os esforços dirigidos somente às mudanças de pretensões culturais não podem ser bem-sucedidas, a menos que a base institucional da sociedade mude para a manutenção e o reforço da visão cultural modificada. Torna-se imprescindível, portanto, que o aparato institucional esteja acompanhado de ações práticas para mudança no padrão cultural que reproduz desigualdades entre homens e mulheres. Além disso, propõe-se que as estratégias adotadas pelos assentados sejam uma fonte de aprendizagem que sirva para iluminar a intervenção pública, aliada a uma política eficiente de assistência técnica.

A despeito dos projetos "fracassados", a principal conclusão desse estudo é que essas mulheres enxergam mais do que uma luz ao final de cada desilusão. Sua persistência e coragem para investir em novos projetos demonstram que elas têm encontrado uma mola no fundo do poço, que as impulsionam novamente para o ponto em que a esperança lhes permite acreditar que há possibilidades de construir uma vida melhor.

\section{Referências bibliográficas}

ALVES, G. Universal e Singular: em discussão a abordagem científica do regional. In: ALVES, G. Mato Grosso do Sul: o universal e o singular. Campo Grande: Ed. UNIDERP, 2003. p. 17-29.

CARNEIRO, M. J. Em que Consiste o Familiar da Agricultura Familiar? In: ORNAs - Ocupações Rurais Não-Agrícolas. Anais da Oficina de Atualização Temática. Londrina, Iapar, 2000, p. 153-164.

DEERE, C. D. e LEON, M. O empoderamento da mulher: direitos à terra e direitos de propriedade na América Latina. Trad. Letícia Vasconcelos Abreu, Paula Azambuja Rossato Antinolfi e Sônia Terezinha Gehering. Porto Alegre: Editora da UFRGS, 2002, p. 52-61. 
FARGE, A. e DAVIS, N. Z. A história das mulheres: do renascimento à idade moderna. Porto: Edições Afrontamento, 1991.

FERRANTE, V. L. S. B. Assentamentos rurais: ações coletivas na contra-mão das idealizações do Estado. In: XXIV Encontro Anual da ANPOCS, 2000, Petrópolis. Anais do XXIV Encontro Anual da ANPOCS, 2000.

FERRANTE, V. L. S. B. e BARONE, L. A. Relações de Gênero nos Assentamentos rurais: violência e resistência na Constituição de um novo modo de vida. In: XXXVII CONGRESSO BRASILEIRO DE ECONOMIA RURAL E FIRST SOBER /IAAE JOINT SYMPOSIUM, 1999, Foz do Iguaçu - PR. Brasília: SOBER, 1999.

FERRANTE, V. L. S. B. e BARONE, L. A. Assentamentos rurais na agenda política do desenvolvimento local: o que desponta no horizonte? (texto digitado) s/d.

LAZZARINI, S. G. Estudos de caso para fins de pesquisa: aplicabilidades e limitações do método. In: FARINA, E. M. M. (Org.). Estudos de caso em agribusiness. São Paulo, 1997.

MARTELO, E. Z. e ZAVALAS, J. L. (Coord.). La integración econômica de las mujeres rurales: um enfoque de gênero. Secretaria de La Reforma Agrária. México, $\mathrm{s} / \mathrm{d}$.

MARTINS, J. de S. Impasses sociais e políticos em relação à reforma agrária e à agricultura familiar no Brasil. Documento apresentado no Seminário Interno sobre "Dilema e perspectivas para o Desenvolvimento
Rural no Brasil, com ênfase no Agrícola e Rural na Primeira década do Século XXI", FAO, Santiago do Chile, 11-13 de dezembro, 2001.

MEDEIROS, L. S. e LEITE, S. Assentamentos rurais: mudança social e dinâmica regional. Rio de Janeiro: Mauad, 2004.

ORTNER, S. Está a mulher para o homem assim como a natureza para a cultura? In: ROSALDO, M. Z. e LAMPHERE, L. A mulher, a cultura e a sociedade. Rio de Janeiro: Paz e Terra, 1979.

PACHECO, M. E. Agricultura familiar: sustentabilidade ambiental e igualdade de gênero. GT GêneroPlataforma de Contrapartes Novib (Org.). Perspectiva de gênero; debates e questões para as ongs. Recife. Luci Artes Gráficas LTDA, 2002, p. 138-161.

RAFFESTIN, C. Por uma geografia do poder. São Paulo: Ática, 1993.

RUA, M. das G. e ABRAMOVAY, M. Companheiras de luta ou "coordenadoras de panelas"? As relações de gênero nos assentamentos rurais. Brasília: UNESCO, 2000.

VALENTE, A. L. E. F. Juventude universitária e processo de formação: uma análise de reações discentes à disciplina Extensão Rural. In: FREITAS, M. C. de (Org.). Desigualdade social e diversidade cultura na infância e na juventude. Vol. 1. São Paulo: Cortes, 2006, p. 259-282.

VALENTE, A. L. E. F. Reflexões sobre o estudo de caso: subsídio à pesquisa no campo do agronegócio, 2003. (texto digitado). 